\title{
EDITORIAL
}

\section{In Memoriam of Professor Zuyan Shen}

\author{
The Editorial Office
}

Tongji University, Shanghai 200092, China

With deep sorrow and respect, we regret to announce that Professor Zuyan Shen, the founder and editor-in-chief of the Frontiers of Structural and Civil Engineering, passed away on October 11, 2017, at the age of 82. As the founder and editor-in-chief, Prof. Shen shaped the journal from its infancy. He was the leading contributor who proposed the scope, the focus, and most importantly, the development strategy of this journal. Prof. Shen conceived the idea of establishing the first comprehensive international journal in civil engineering discipline in China. Therefore, he founded the journal in 2006, with the first issue officially published in January 2007 . To promote the quality of the journal and its international impact, he invited numerous internationally renowned scholars to join the editorial board. With his sustained efforts over the years, the journal has rapidly gained its reputation in civil engineering among our colleagues in both academia and industry.

On behalf of the editorial board, we respectfully convey this tribute as the editorial of the journal to our international readers. Commensurate with this opportunity, we would like to share with you the lifelong contributions to the field of civil engineering made by Prof. Shen, who enjoyed a high reputation for his excellence in both research and education in China and internationally.

Prof. Zuyan Shen started his undergraduate study in September 1951 in the Department of Civil Engineering, Shanghai Jiao Tong University. One year later, he was transferred as an undergraduate student to Tongji University because of the reforming of the Civil Engineering disciplines, in which several universities were involved. After he received his BEng degree in 1955, he started to work at Tongji University, where he spent the rest of his life for more than 60 years.

Prof. Shen had dedicated his life to pursue research on steel structures, particularly on the stability of steel structures in his career. In the 1980s, he developed numerical methods for nonlinear analysis of stability and load bearing capacity of steel structures. He proposed formulations for estimating the overall stability of beam-columns subjected to bending and compression, and angle steel components subjected to axial compression. He also developed a large displacement elastoplastic method for stability analysis of long-span spatial steel structures with initial imperfections.

Prof. Shen devoted himself to the failure and fracture analysis and damage evaluation of steel structures subjected to earthquakes. He developed constitutive models for steel materials under cyclic loading and hysteresis models for steel members. His generalized computational methods for static and dynamic analyses of large span and high-rise steel structures that started to be widely adopted in the 1990s in China. By providing technical support from experimental and analytical investigations to design guidelines, he was involved in the construction of many landmark buildings in China, including the Shanghai Oriental Pearl Television Tower, Shanghai Stadium, Pudong International Airport Terminal Buildings, China Central Television Tower (new site), National Opera House, and Shanghai Tower. Prof. Shen was a great educator, a distinguished mentor and supervisor. He established many new concepts in the education of civil engineering. His undergraduate course "Steel Structures" was selected by the Chinese Ministry of Education as the "National High Quality Curriculum" of Higher Education for Civil Engineering Discipline. His textbooks based on his lecture notes of Steel Structure have been widely adopted at universities in China, and were awarded the National Prize of Excellent Books for Teaching. During the past six decades, he supervised 70 master students and 63 doctoral students. Those graduates are now working all over the world. Some of them have become faculty members at universities, some of them work as researchers in various institutes, and some are leading experts in industry.

Prof. Shen was a special contributor to the development of the education programme of Civil Engineering in Chinese universities. He chaired the Steering Committee for the Higher Education of Civil Engineering in China. 
During his appointment, he promoted the expansion of the educational programme of Construction and Building related disciplines in China. He was a pioneer of this new concept of education programme. He spared no efforts in transforming the conventional education programme from the "profession specific oriented mode" to a "general engineering profession oriented mode", resulting in enhanced competiveness of numerous students for a broader range of engineering professions after their college graduation.

Prof. Shen chaired for many years the National Board of Civil Engineering Accreditation of China. He founded a domestic accreditation system which was connected to the Charted Engineer system in the U.K., where the mutual recognitions between China and the U.K. were successfully established. During his life, he was appointed many important positions, including the vice president of Tongji University, the director of China National Key Laboratory for Disaster Prevention and Reduction in Civil Engineering, and the head of Shanghai Disaster Relief Institute. In addition, his extensive services in national and international societies greatly contributed to the promotion of the academic impact of China.

Prof. Shen was awarded numerous national science and technology prizes from the Chinese government. Due to his achievement, he was elected as a member of Chinese Academy of Engineering in 2005. He was a fellow of the Institution of Civil Engineers (FICE) and a fellow of the Institution of Structural Engineers (FIStructE) in the U.K..

He will be deeply missed by all of us, especially those who had worked with him for the journal. We will respectfully follow his great mind, and we believe that his impact on the journal will live with us forever, way beyond the time frame he was with us. 